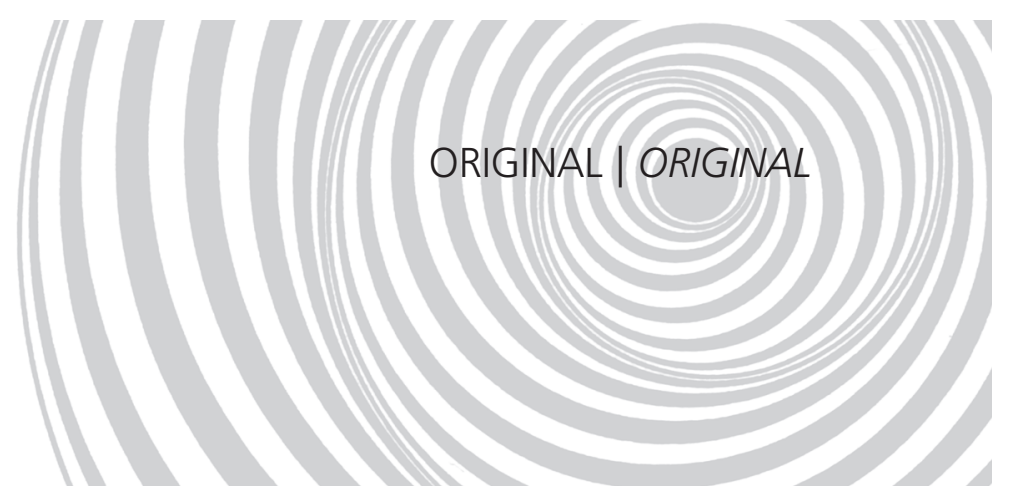

\title{
O fazer teórico-prático do nutricionista na estratégia saúde da família: representações sociais dos profissionais das equipes ${ }^{1}$
}

\author{
What dieticians do, in practice and in theory, \\ in the family health strategy: views of \\ health team professionals
}

Ana Cristina do Amaral CAMOSSA ${ }^{2}$

Rodolpho TELAROLLI JUNIOR²

Maria Lúcia Teixeira MACHADO3

RE S U M O

\section{Objetivo}

Conhecer as representações sociais dos profissionais das equipes de saúde da família sobre o fazer teórico-prático do nutricionista. A pesquisa foi realizada em Unidades de Saúde da Família de um município do estado de São Paulo.

\section{Métodos}

Foi utilizada a metodologia qualitativa, tendo como sujeitos 27 profissionais, eleitos por critério intencional. A coleta de dados foi realizada por meio de entrevistas semiestruturadas. Para a interpretação dos dados, utilizou-se a análise categorial temática, apropriando-se da Teoria das Representações Sociais.

\section{Resultados}

Como resultados, emergiram quatro temas: Nutricionista na Estratégia de Saúde da Família, Abordagem de questões alimentares pelos profissionais da equipe de saúde da família, Educação nutricional e Problematizando a ausência do nutricionista na equipe de saúde da família. As principais representações obtidas com relação ao nutricionista foram relacionadas à prescrição de dietas, além de revelarem um conhecimento mais amplo sobre as funções e atribuições desse profissional. Não houve dúvidas sobre a importância da educação nutricional na promoção de práticas alimentares saudáveis, apesar de os sujeitos terem demonstrado uma visão superficial e pouco abalizada teoricamente sobre o tema.

\footnotetext{
1 Artigo elaborado a partir da dissertação de ACA CAMOSSA, intitulada "O fazer teórico-prático do nutricionista na estratégia saúde da família: representações sociais dos profissionais das equipes". Universidade Estadual Paulista Júlio de Mesquita Filho; 2010

2 Universidade Estadual Paulista Júlio de Mesquita Filho, Faculdade de Ciências Farmacêuticas, Curso de Alimentos e Nutrição. Rod. Araraquara/Jaú, Km 1, 14801-902, Araraquara, SP, Brasil. Correspondência para/Correspondence to: ACA CAMOSSA. E-mails: <tinacamossa@gmail.com>; <tinacamossa@ig.com.br>.

${ }^{3}$ Universidade Federal de São Carlos, Departamento de Enfermagem. São Carlos, SP, Brasil.
} 
90 | ACA CAMOSSA et al.

\section{Conclusão}

A ausência do nutricionista na equipe de saúde da família foi atribuída a fatores como o baixo reconhecimento social, a desvalorização profissional, o pouco tempo de existência da profissão, o desconhecimento do núcleo de competência do nutricionista e a manutenção do modelo médico hegemônico. Concluiu-se pela necessidade de mais estudos que problematizem a inserção do nutricionista em equipes de saúde da família.

Termos de indexação: Educação alimentar e nutricional. Nutricionista. Percepção social. Saúde da família.

\section{A B S T R A C T}

\section{Objective}

The objective of this study was to investigate how professionals in family health teams view what dieticians do in practice and in theory. The study was done in Family Healthcare Units of a municipality in the state of São Paulo.

\section{Methods}

The qualitative methodology was used on 27 deliberately chosen professionals. Semi-structured interviews were used to collect data. Thematic analysis and the Social Representation Theory were used for data interpretation.

\section{Results}

Four themes emerged from the analysis: dietician in the family health strategy; family health team's approach to dietary issues; nutrition education; and problematizing the absence of a dietician in the family health team. Dieticians were mainly viewed as individuals who prescribe diets. Nevertheless, the interviewees proved to have good knowledge about dieticians' functions and attributions. The importance of nutrition education for the promotion of healthy food practices was beyond doubt, even though the interviewees' views on the theme were superficial and poorly grounded.

\section{Conclusion}

The absence of a dietician in the family health team was attributed to the following factors: low social recognition, professional devaluation, relatively new profession, unfamiliarity with the core competence of the dietician and maintenance of the hegemonic medical model. In conclusion, more studies are necessary to problematize the insertion of dieticians in family health teams.

Indexing terms: Food and nutrition education. Nutritionist. Social perception. Family health.

\section{N T R O D U Ç Ã O}

No cenário mundial, a Nutrição, seja como ciência ou como profissão, é um campo relativamente recente, do início do século XX. Mais especificamente no Brasil, surgiu no decorrer dos anos 1930-1940, tendo como uma de suas vertentes a Nutrição em Saúde Pública ou Nutrição em Saúde Coletiva.

Estudos anteriores demonstraram que a Nutrição em Saúde Coletiva absorvia um número bastante inferior de nutricionistas em relação às áreas de clínica e alimentação institucional ${ }^{1-3}$.

Embora a Estratégia Saúde da Família (ESF), entendida como uma proposta de renovação do modelo de assistência à saúde desen- volvido a partir da atenção básica, preconize o trabalho interdisciplinar e multiprofissional, o que se observa na prática é uma ampla predominância de equipes que contam apenas com médicos, enfermeiros e dentistas ${ }^{4}$. Uma avaliação realizada pelo Ministério da Saúde revelou que em menos de $5 \%$ das equipes de saúde da família havia profissionais da área de nutrição atuando ${ }^{5}$.

Dentro desse enfoque, em 2008, o Ministério da Saúde oficializou o campo de trabalho na área de atenção básica para os nutricionistas por meio dos Núcleos de Apoio à Saúde da Família (NASF), com o objetivo de ampliar a abrangência e o escopo das ações da atenção básica, bem como sua resolubilidade. Nestes, o nutricionista teria como atribuições ${ }^{6}$. 
Coordenação das ações de diagnóstico populacional da situação alimentar e nutricional; promoção da alimentação saudável para todas as fases do curso da vida; estímulo à produção e o consumo dos alimentos saudáveis produzidos regionalmente; capacitação da ESF e participação de ações vinculadas aos programas de controle e prevenção dos distúrbios nutricionais como carências por micronutrientes, sobrepeso, obesidade, doenças crônicas não transmissíveis e desnutrição; elaboração das rotinas de atenção nutricional e atendimento para doenças relacionadas à Alimentação e Nutrição, de acordo com protocolos de atenção básica, organizando a referência e a contra-referência do atendimento; e promoção da articulação intersetorial para viabilizar as ações voltadas para a Segurança Alimentar e Nutricional (p.28).

Dados mais atuais evidenciam a instalação do NASF em quase todos os municípios com mais de 200 mil habitantes, sendo que o profissional nutricionista está presente em 536 (70,8\%) dos 757 NASF implantados até julho de 20097 .

O município estudado, a despeito de contar com projetos de implantação do NASF, vem experienciando a inserção do nutricionista, dentre outros profissionais, em algumas Unidades de Saúde da Família (USF), por meio do programa de Residência Multiprofissional em Saúde da Família e Comunidade, oferecido pela Universidade Federal de São Carlos em parceria com a Secretaria Municipal de Saúde do município.

Nesse contexto, a educação nutricional constitui importante estratégia de ação em Saúde Coletiva; é disciplina obrigatória nos cursos de nutrição e deve fazer parte das ações do nutricionista em todos os campos de atuação.

Apesar de ter ficado durante muito tempo no exílio ${ }^{8}$, a educação nutricional sempre esteve e continua presente na prática profissional dos nutricionistas e, segundo a lei de regulamentação da profissão, constitui atividade privativa desse profissional. Segundo Monteiro et al..$^{9}$ a educação nutricional é apontada como estratégia de ação a ser adotada prioritariamente em saúde coletiva para conter o avanço da prevalência de doenças crônicas não transmissíveis. Os autores recomendam, ainda, que se reserve "lugar de destaque a ações de educação em alimentação e nutrição que alcancem de modo eficaz todos os estratos econômicos da população"g (p.254).

Atualmente, a promoção de práticas alimentares e estilos de vida saudáveis faz parte das diretrizes da Política Nacional de Alimentação e Nutrição (PNAN), do Ministério da Saúde, e apresenta interface importante com a Segurança Alimentar e Nutricional (SAN), que tem como meta a reconstrução de um mundo livre de fome ${ }^{10,11}$. Porém, há um paradoxo: ao mesmo tempo que a educação nutricional é valorizada, ela se dilui num conjunto de propostas, na medida em que não estão estabelecidas claramente as bases teórico-conceituais e operacionais que a fundamentam. Seu espaço não se apresenta claramente definido: a educação nutricional está em todos os lugares, mas não está em nenhum lugar definido?.

É inegável a importância de ações de educação nutricional em todos os programas de saúde, pois a mesma está inserida na educação em saúde, que tem por finalidade a formação de atitudes e práticas conducentes à saúde. Vários trabalhos mostram a receptividade, o interesse e a necessidade social de ações educativas na área de Alimentação e Nutrição. Entretanto, Boog ${ }^{12}$ evidencia que inexiste o espaço institucional da educação nutricional, entendido por cargos e funções nos serviços públicos de saúde. A constatação da pouca inserção do profissional nutricionista na rede de atenção básica à saúde até o momento, como já colocado anteriormente, e, consequentemente, a carência de ações de educação nutricional, levou a alguns questionamentos que serão discutidos no presente trabalho.

Considerando o exposto, o objetivo deste trabalho foi conhecer as representações sociais, construídas por profissionais das equipes de saúde da família, sobre o fazer teórico-prático do nutricionista. 


\section{MÉTODOS}

Trata-se de uma pesquisa qualitativa fundamentada teoricamente no construto da Teoria das Representações Sociais. A abordagem qualitativa foi eleita devido à complexidade do campo da saúde e à natureza do objeto de estudo, uma vez que, como destaca Minayo ${ }^{13}$, essa modalidade de pesquisa permite verificar os significados atribuídos pelos sujeitos à realidade de suas práticas, além de visar ao aprofundamento no mundo dos significados, relações humanas, atitudes, crenças e valores. Nessa abordagem, segundo a autora, não há preocupação em quantificar, mas, sim, em compreender e explicar a dinâmica das relações sociais. Como marco teórico-metodológico, a Teoria das Representações Sociais lida com os aspectos psicossociais do cotidiano dos sujeitos da pesquisa, contribuindo para conhecer a imagem de um determinado objeto formulada por determinados sujeitos.

Para Moscovici ${ }^{14}$, criador do conceito, as representações sociais são como "uma modalidade de conhecimento particular que tem por função a elaboração de comportamentos e a comunicação entre os indivíduos"14 (p.26). Assim, conforme o autor, a representação produz e determina comportamentos.

Por representações sociais, entendemos um conjunto de conceitos, proposições e explicações, originado na vida cotidiana no curso de comunicações interpessoais. Elas são o equivalente, em nossa sociedade, dos mitos e sistemas de crenças das sociedades tradicionais; podem também ser vistas como a versão contemporânea do senso comum ${ }^{14}$ (p.181).

As representações sociais são entendidas como um saber presente no senso comum e refletido no cotidiano de determinado grupo social. Trata-se de um conhecimento que circula da ciência para o senso comum e vice-versa. Dessa forma, são consideradas "teorias" sobre saberes populares e do senso comum, elaboradas e partilhadas coletivamente, com a finalidade de cons- truir e interpretar o real. Nesse sentido, uma representação pode ser acessada por informações, opiniões e atitudes a propósito de um dado objeto social ${ }^{15}$.

Para Cabecinhas ${ }^{16}$, as representações sociais podem ser representativas de determinado grupo social, influenciando na forma como outros grupos o percebem e se relacionam com ele. Elas contribuem para definir um grupo social em sua especificidade. Assim, as representações sociais possuem como materiais fundamentais de estudo as concepções verbalizadas, as atitudes e os julgamentos individuais e coletivos sobre determinada realidade.

Este estudo foi realizado no município de São Carlos, interior do estado de São Paulo, uma das macrorregiões mais desenvolvidas do Brasil. É importante lembrar que a política de saúde foi bastante incipiente no município até o final do ano 2000 , visto que a rede básica não era expressiva até essa data ${ }^{17}$. Uma nova gestão do município, a partir de 2001, abriu possibilidades de mudanças nessa história. Dessa forma, o modelo de atenção vem sendo transformado progressivamente, por meio da adoção da ESF como eixo estruturante da rede de atenção básica à saúde.

Nesse contexto, o programa de Residência Multiprofissional em Saúde da Família e Comunidade configurou-se numa iniciativa pioneira de inserção do profissional nutricionista na rede de atenção básica à saúde, proporcionando ao município o conjunto de atributos pertinentes ao que se pretende investigar neste estudo.

Os sujeitos do estudo foram 21 profissionais de duas equipes de saúde da família e 6 residentes, além da diretora do Departamento de Gestão e Cuidado Ambulatorial da Secretaria de Saúde do município de São Carlos (SP). O critério para eleger o número de pessoas foi intencional, por se tratar de sujeitos-chave nas equipes multiprofissionais da ESF, tratando-se de uma amostra não probabilística.

Os dados foram coletados no período de dezembro de 2008 a maio de 2009, por meio de 
entrevistas semiestruturadas e informações documentais. As entrevistas foram gravadas na totalidade e, posteriormente, transcritas na íntegra, com a finalidade de garantir a fidedignidade das falas dos sujeitos. Após a transcrição, foram identificadas de acordo com a categoria profissional e a ordem de realização da entrevista, a fim de respeitar o anonimato dos participantes.

Para análise dos dados, foi utilizada a abordagem hermenêutica-dialética, que tem como fundamento a compreensão, no que diz respeito à possibilidade de interpretar, estabelecer relações e extrair conclusões, por meio de uma atitude crítica de estudo da realidade social. A orientação dialética de qualquer análise supõe a crítica das ideias expostas nos textos (ou entrevistas), buscando sempre sua especificidade histórica, superando o formalismo das análises de conteúdo e do discurso tradicionais ${ }^{13}$.

Desse modo, após a transcrição das gravações e a organização do texto, fez-se uma leitura preliminar, buscando uma familiarização com a descrição das falas. Posteriormente, foram organizados os aspectos principais de cada depoimento em uma primeira fase da categorização, seguindo a sequência das questões principais do roteiro de entrevista. Em seguida, foi realizada uma análise bruta do conjunto dos depoimentos por questão formulada, o que constituiu a segunda fase da categorização, buscando reunir todas as informações obtidas para determinado tema, facilitando a visualização do conjunto. Enfim, foi realizada uma leitura seletiva e aprofundada dos temas, para, em seguida, identificar no conjunto das informações levantadas as possíveis representações sociais ali contidas.

O projeto de pesquisa foi aprovado pelo parecer n 32/2008, do Comitê de Ética em Pesquisa da Faculdade de Ciências Farmacêuticas da Universidade Estadual Paulista Júlio de Mesquita Filho (UNESP), emitido em 4 de novembro de 2008, que considerou o projeto estruturado dentro de padrões éticos e em conformidade com as orientações constantes da Resolução 196/96 do Conselho Nacional de Saúde do Ministério da Saúde. Todos os participantes assinaram um Termo de Consentimento Livre e Esclarecido antes de sua inclusão na amostra.

\section{RESULTADOSE DISCUSSÃO}

Fizeram parte dessa pesquisa as seguintes categorias profissionais: médico (2), enfermeiro (4), dentista (2), nutricionista (2), educador físico (2), auxiliar de enfermagem (3), auxiliar odontológico (2), Agente Comunitário de Saúde (ACS; 10), totalizando 27 profissionais de saúde, dos quais 21 eram profissionais da equipe e 6 eram residentes (Tabela 1).

Quanto ao sexo, observou-se a predominância do sexo feminino, compatível com outros dados que revelam uma tendência à feminização das profissões no mercado de trabalho em saúde.

No presente estudo, as duas residentes nutricionistas eram do sexo feminino. Esses dados estão em acordo com pesquisa recente do CFN, que encontrou $96,5 \%$ de nutricionistas do sexo feminino no Brasil' 1 . Nesse sentido, destaca-se que a categoria é composta quase que exclusivamente por mulheres, característica que se associa a diversos elementos presentes na história desse profissional, já que o direcionamento para a formação de mulheres no campo da Nutrição vem sendo fortalecido desde a gênese dos primeiros cursos de formação ${ }^{3}$.

Para alguns autores, historicamente a associação da Nutrição com o sexo feminino tem implicado um menor prestígio para quem a exerce, o que em parte se explica pelo fato de essas ocupações, em algumas situações, desempenharem, no mundo do trabalho, atividades equivalentes àquelas que as mulheres desempenham em casa $^{3,18}$.

Em relação ao perfil dos sujeitos, os resultados mostraram maior prevalência, entre os residentes, da faixa etária de 20 a 29 anos, caracterizados como adultos jovens. Entre os profissionais 
94 | ACA CAMOSSA et al.

Tabela 1. Perfil dos profissionais de saúde de equipes de saúde da família, de acordo com sexo, idade e tempo de serviço. Secretaria Municipal de Saúde de São Carlos (SP), 2009.

\begin{tabular}{|c|c|c|c|c|c|c|c|c|c|}
\hline \multirow[b]{2}{*}{ Itens } & \multicolumn{9}{|c|}{ Categoria Profissional } \\
\hline & Médico & Enfermeiro & Dentista & Nutriconista & $\begin{array}{c}\text { Educador } \\
\text { Físico }\end{array}$ & $\begin{array}{c}\text { Auxiliar } \\
\text { Enfermagem }\end{array}$ & ACS & $\begin{array}{c}\text { Auxiliar } \\
\text { Odontológico }\end{array}$ & Total \\
\hline \multicolumn{10}{|l|}{ Sexo } \\
\hline Feminino & 1 & 3 & 2 & 2 & 2 & 3 & 10 & 2 & 25 \\
\hline Masculino & 1 & 1 & - & - & - & - & - & - & 2 \\
\hline \multicolumn{10}{|c|}{ Vínculo com a USF } \\
\hline Equipe & 2 & 2 & 2 & - & - & 3 & 10 & 2 & 21 \\
\hline Residente & - & 2 & - & 2 & 2 & - & - & - & 6 \\
\hline \multicolumn{10}{|c|}{ Faixa etária (anos) } \\
\hline $20-29$ & - & 3 & - & 1 & 1 & - & 5 & - & 10 \\
\hline $30-39$ & - & - & 1 & 1 & 1 & 3 & 1 & 1 & 8 \\
\hline $40-49$ & 2 & 1 & - & - & - & - & 2 & - & 5 \\
\hline $50-59$ & - & - & 1 & - & - & - & 1 & 1 & 3 \\
\hline$\geq 60$ & - & - & - & - & - & - & 1 & - & 1 \\
\hline \multicolumn{10}{|c|}{ Tempo de serviço no PSF (anos) } \\
\hline$<1$ & - & 2 & - & - & - & - & 1 & 1 & 4 \\
\hline $1-5$ & 1 & 1 & 1 & 2 & 2 & 3 & 9 & 1 & 20 \\
\hline $6-10$ & 1 & 1 & 1 & - & - & - & - & - & 3 \\
\hline
\end{tabular}

USF: Unidade de Saúde da Família; PSF: Programa Saúde da Família; ACS: Agente Comunitário de Saúde.

Fonte: Entrevistas realizadas no período de novembro de 2008 a maio de 2009, durante a pesquisa de campo.

de nível superior, a faixa etária mais prevalente foi a de 40 a 49 anos, e, entre os profissionais de nível médio, de 20 a 39 anos. Todos os profissionais de nível superior entrevistados possuíam pós-graduação em Saúde da Família.

Da análise dos dados, emergiram as categorias empíricas que serão discutidas a seguir.

\section{O nutricionista na estratégia saúde da família}

Um dos fatores relevantes para a construção das representações sociais sobre o fazer teórico-prático do nutricionista foi a ocorrência de experiências prévias dos participantes com o profissional, seja por meio de contatos pessoais ou profissionais anteriores. De um modo geral, a maioria dos profissionais não tinha conhecimento prévio sobre o trabalho do nutricionista, e passou a conhecê-lo após a inserção do residente em nutrição na unidade.
A maioria das entrevistas revelou semelhanças entre as ações propostas oficialmente para o nutricionista em documentos oficiais ${ }^{6,19} \mathrm{e}$ aquelas obtidas nos relatos dos sujeitos do estudo em questão. Observou-se que os profissionais de saúde associaram o nutricionista à prevenção e promoção da saúde, elementos estes presentes em grande parte dos relatos observados.

\begin{abstract}
A função da nutricionista nesse caso é essencial... Então, eu acho que seria mais na parte de promoção da saúde ... poderia ser com grupos ... e não atuar depois que o problema tá instalado. Isso daí, às vezes, a gente chega até a pensar que é uma utopia você trabalhar só com promoção de saúde. Mas eu acho que a gente tem que começar (ACS-20).
\end{abstract}

Além dessas, também apareceram como atividades do nutricionista na ESF a orientação e a elaboração de dietas para doenças crônicas:

... com diabéticos, hipertensos, tá fazendo esse controle, então, através de grupos, 
a gente tem grupo de diabéticos ... fazendo mesmo atendimento individual, mas, assim, de pessoas descompensadas, tá? (ACS-7).

Dessa forma, contrariando as representações anteriores, a compreensão de que o nutricionista só pode atuar quando houver um problema alimentar já estabelecido, como no caso das doenças crônicas, descaracteriza as ações de promoção à alimentação saudável e prevenção de distúrbios relacionados à nutrição, característicos do profissional.

Outras ações do profissional nutricionista bastante citadas pelos entrevistados foram as ações educativas em grupo e as Visitas Domiciliares. Pelos relatos, pôde-se verificar que a visita domiciliar foi uma estratégia bastante utilizada pelo nutricionista nas USF estudadas, permitindo o estreitamento do vínculo entre profissional e usuário e favorecendo maior entendimento e adesão ao tratamento, o que possibilitou a realização de práticas de intervenção nutricional mais adequadas à realidade da população assistida.

Por outro lado, apareceram, nas falas de alguns sujeitos, representações com uma visão bastante restrita do trabalho do nutricionista, caracterizadas pelas expressões: "nutricionista é o profissional que passa dieta", "nutricionista é para perder peso", "controla a dieta dos pacientes" e "passa receitas". Um dos sujeitos da pesquisa utilizou a metáfora "vocês são os médicos dos alimentos!" para expressar sua representação acerca do profissional nutricionista, mostrando certa confusão de papéis profissionais.

Como pode ser observado na fala a seguir, uma representação social da prática do nutricionista na ESF foi a de auxiliar e facilitar o trabalho dos médicos:

Mas, eu acho que facilitou demais o meu trabalho aqui na unidade a partir do momento que a residente nutricionista esteve aqui, ou veio pra cá... Então, pra mim, deu um suporte que, na verdade, a gente avalia, a gente orienta, mas aquelas
... o que a gente tem que estar fazendo, realmente, de acompanhamento, a gente até acompanha peso, não sei o que, não sei o que lá, mas ... o stress do dia a dia, a atenção que a gente tem que dar pra cada paciente é muito grande e, às vezes, tem coisas específicas que a gente não dá conta, entendeu? Não que a gente não tenha capacidade, mas, na hora, foge, que não é uma coisa da rotina nossa. Aqui, o nutricionista, ele me ajuda muito, [a residente de nutrição] me ajuda muito na parte, realmente nutricional, de educação em saúde, na parte alimentar (Médico-4).

Essa visão do trabalho do nutricionista com a finalidade de poupar tempo e dar suporte ao trabalho médico já foi discutida anteriormente em outros estudos ${ }^{8,20}$, nos quais o nutricionista foi considerado um profissional que depende do médico para atuar e é visto como coadjuvante do trabalho desse profissional. Para Boog ${ }^{8}$, essa percepção restrita das possibilidades de atuação do profissional acaba, muitas vezes, limitando uma inserção mais efetiva do nutricionista na assistência direta ao paciente.

Contudo, os resultados da presente pesquisa mostraram algumas mudanças na visão do papel do profissional, visto que alguns relatos demonstraram conhecimento de maior número de funções e atribuições do nutricionista. Talvez isso se explique pela inserção da categoria de nutricionistas no município por meio do programa de residência, o que permitiu maior aproximação da equipe com os profissionais de nutrição, possibilitando um rompimento com a visão restrita sobre a área e, consequentemente, aumentando o conhecimento sobre a atuação profissional do nutricionista.

\section{Abordagem de questões relativas à alimentação e nutrição pela equipe de saúde da família}

De um modo geral, a abordagem de questões relativas à alimentação e nutrição foi relatada 
como superficial e realizada de forma não sistematizada, como demonstram os relatos.

Eu pergunto mesmo, que nem, no caso do hipertenso que nunca abaixa a pressão, eu falo "como você faz a alimentação?" "pouco sal?" "você bebe muita água?" "tem gordura?" "muita gordura?" E ele vai me passando, e eu vou começar a cortar, a diminuir a gordura, o sal, trocar o sal mais pelo tempero natural (ACS-2).

Outros estudos também revelaram que a abordagem é feita geralmente por médicos e enfermeiros, restringindo-se a orientações alimentares limitadas, sem a ocorrência de outras atividades além dessas orientações ${ }^{2,12}$. Em estudo realizado no município de Campinas (SP), Pádua $\&$ Boog $^{2}$ relacionaram a ausência de nutricionistas trabalhando na rede básica de saúde com o fato de as orientações alimentares serem repassadas por outros profissionais de saúde, situação semelhante à do município estudado no presente trabalho.

Em muitos casos, a orientação alimentar é feita por meio da entrega de "dietas prontas" que são repassadas para os usuários. Destacam-se, a seguir, alguns depoimentos que buscam ilustrar essa questão.

... tem as dietas que a gente distribui pros pacientes, dieta do hipertenso, dieta do diabético, dieta do colesterol, dieta do ácido úrico, e assim por diante. Então, quem acaba orientando é a gente ... (ACS-13).

A gente tem uma folhinha aqui de dieta, e passa. Orienta os alimentos que são permitidos, moderados e proibidos (Residente-15).

Concordando com a afirmação de Diez-Garcia²1 (p.285) "a imposição de modelos dietéticos pautados na racionalidade nutricional restringe a alimentação à sua relação com a saúde e a doença, que são os propulsores de intervenções nutricionais". Dessa forma, quando se tenta impor a adoção de um ou outro modelo de dieta, ou mesmo recomendações pontuais de inclusão e exclusão de alimentos, negligencia-se a cultura alimentar do indivíduo, por não se levar em consideração o impacto e a forma como essas mudanças propostas serão absorvidas por ele. Assim, quando se substitui uma orientação alimentar adequada por uma "folhinha de dieta", não se realiza uma assistência nutricional efetiva.

O relato a seguir sugere uma abordagem baseada em intervenções impositivas e normativas, caracterizadas por prescrições comportamentais que desconsideram a complexidade das práticas alimentares. Prescrições realizadas dessa forma podem representar uma intromissão de cunho impessoal, técnico e objetivo em situações do campo pessoal, afetivo e subjetivo, causando geralmente resistência ao seu cumprimento 22 .

Eu costumo me meter mesmo, como eu te falei, né? Não me dê uma coxinha pra uma criança na hora do almoço, não me dê um saquinho de "fandango"! Depois do almoço, de tardezinha, tá vendo televisão, até pode um "fandango" ou uma pipoca. Mas, se a criança gostar de uma fruta, dá uma fruta! Se você puder dar uma fruta, dá uma fruta. Se ela quiser comer uma bacia de laranja, e você tem, dá a bacia de laranja! Nunca vai fazer mal ... eu tenho uma diabética aqui que eu pego no pé. Porque ela tomava leite condensado na latinha. E eu falava assim, "E o leite condensado, vai bem?", sempre eu falava. "Só um pouquinho?" Eu falava, "Nem um pouquinho. Esse pouquinho todo dia vai virar um poucão. E esse poucão vai te tirar de mim. E o que vai ser de mim sem você? Vou ficar triste, né?" Ela falava assim: "Você quer chá?" "Não, hoje não" "Eu ponho leite condensado" "Ahhhhhhh!!! Você põe leite condensado??? Que bonito, né? Diabética comendo leite condensado!!! Põe um pouquinho de adoçante que fica uma delícia, chá com adoçante é bom! E com o cookie, nossa, ai que é bom, é gostoso mesmo, não faz mal. E a aveia é legal 
porque faz o intestino funcionar". As minhas estratégias são sempre assim ... Com jeitinho, eles acabam fazendo aquilo que a gente quer que eles façam (grifo dos autores) (ACS-22).

Os entrevistados relataram enfrentar várias dificuldades na abordagem das questões de alimentação e nutrição de seus clientes, sendo que a principal dificuldade manifestada foi a falta de conhecimento técnico para fazer a orientação nutricional. Esses dados estão de acordo com estudo que revelou que a maioria dos médicos e enfermeiros considera seus conhecimentos deficientes nessa área ${ }^{12}$.

Os profissionais entrevistados também manifestaram uma demanda por capacitação na área de nutrição, revelando que a falta de treinamento no município pode estar relacionada às dificuldades para a abordagem de questões alimentares.

Outra dificuldade bastante mencionada foi a falta de tempo para fazer abordagens em nutrição. Esses relatos coadunam-se com as representações anteriores sobre como os profissionais percebem o trabalho do nutricionista, com a finalidade de poupar tempo e dar suporte ao trabalho médico.

E pra você explicar, tem que sentar e perder uma hora, ele [o médico] também tá em dificuldade, porque a rotina é muito corrida, né? ... é o tempo ... é. Porque a técnica, você senta com um livro e você lê ele, que você já adquire, agora, o tempo é complicado. Você pára com um paciente uma meia hora e já fica tudo acumulado (ACS-2).

O próprio profissional médico entende que demandar a orientação nutricional para o nutricionista é uma decisão que tem por finalidade otimizar o tempo da consulta médica, e não porque o nutricionista seria o profissional mais capacitado para executar essa atividade, conforme sugere o seguinte depoimento.

Eu recebi uns encaminhamentos feitos pelo médico, aonde ele registrava que pela demora na consulta em orientar hábitos alimentares, alimentação, ele pedia minha avaliação do paciente. ... eu tenho uma outra visão do atendimento, então eu jamais faria um atendimento em 15 min. Mas aí como ele justifica que tem muita demanda, muitos atendimentos, então ele tem que ser rápido, então ele não pode focar isso, então isso é trabalho do nutricionista, não é trabalho da equipe (Residente-16).

Nesse caso, fica claro que o médico fez os encaminhamentos para o nutricionista residente com o objetivo precípuo de não perder tempo com a orientação nutricional, parecendo ter desconsiderado a especificidade do profissional, que é justamente a de prestar a assistência nutricional qualificada.

Somando-se a isso, outra questão que sobressaiu foi a dificuldade de orientação diante do baixo poder aquisitivo que atinge a população usuária desses serviços de saúde.
A dificuldade que eu vejo é, por exemplo, é realmente o poder aquisitivo. Porque eles sabem comer arroz e feijão, não que isso seja ruim, mas a parte de legumes, verduras, não têm hábito, entendeu? E eles acham caro, trabalhoso, o problema é o trabalhoso, tem que lavar, então, tem muitas coisas disso daí, eu acho que o pro- blema é a parte, realmente, de aprender a fazer de uma forma prazerosa, eu acre- dito, tá? (Médico-4).

Esses resultados são similares aos de Boog $^{12}$, para quem os profissionais de saúde não conseguem perceber os problemas alimentares em todas as suas dimensões, muitas vezes confundindo-os com problemas de ordem estritamente econômica. Boog afirma que:

A dimensão universal da questão ali-
mentar, evidenciada no problema da
fome, ignora a dimensão singular do
problema alimentar do indivíduo que
pode não estar diretamente relacionado 
à falta de recursos. A dieta pode até ser simples. Como tratar o problema alimentar é o grande desafio ${ }^{12}$ (p.267).

No entanto, em direção oposta, chamou a atenção o relato de uma ACS, que destaca a pertinência da educação nutricional para lidar com os problemas alimentares quando claramente a família enfrenta problemas socioeconômicos.

... teve já um agente de saúde aqui que uma vez foi fazer a visita e a pessoa falou pra ele "ó, não vem com esse negócio de dieta, com esse negócio de alimentação, porque eu como o que tem na mesa!" Só que é assim, pode substituir por coisas que, por frutas da época, verduras da época, então você pode comer bem com verduras da época que é bem mais barato. Então a população não entende isso, então tem que educar, e não é de um dia pro outro, né? Isso é que é educação nutricional (ACS-3).

O próximo depoimento ilustra de forma bastante interessante a dificuldade de alguns profissionais na abordagem das questões práticas da alimentação dos pacientes, deixando claro que, algumas vezes, o profissional não nutricionista tem até certo conhecimento teórico sobre nutrição e dietoterapia, mas não consegue traduzir essa teoria em orientação prática. Nas palavras desse profissional, a maior dificuldade em orientar os pacientes seria traduzir a prescrição dietética em alimentos, "em alimento comestivel, e não em alimento do laboratório que tem tanto de ferro e tanto de proteína ... por exemplo, transformar essa orientação em dieta no prato, em quantidade, em como fazer ..." , ou seja, transformar o teórico em prático.

Então, a dificuldade que a gente encontra como médico nesse momento é principalmente em questões um pouco mais práticas de como ele tá preparando seu alimento, é lá na beira do fogão. A gente pode falar pra ele que ele não pode ingerir uma quantidade maior do que $250 \mathrm{~mL}$ de óleo por mês, mas como que ele vai fazer os alimentos só com essa quanti-dade? A gente pode dizer pra ele que ele não pode ingerir uma quantidade maior do que $6 \mathrm{~g}$ de sódio por dia, mas como que ele vai tá utilizando de outro tempero pra não deixar a comida com sabor insosso quando se faz isso? Por exemplo, eu tenho um paciente aqui que tem insuficiência hepática, em que ele não pode ingerir nenhum tipo de gordura animal, que ele tem confusão mental. Então, a gente orientou sojas, além de verduras, legumes e frutas, e carboidratos, porém, como ele fazer um bife de soja, como ele tá fazendo uma salada com soja, que é pra suprir as proteínas, porque ele não pode proteínas de cadeia aromática, só de cadeia ramificada. Então, a gente encontra dificuldades na prática, da lida na beira do fogão (grifo dos autores) Essa é minha maior dificuldade (Médico-10).

Uma das ferramentas essenciais que subsidiam a prática do nutricionista é a técnica dietética, disciplina que estuda as operações a que são submetidos os alimentos e as modificações estruturais e organolépticas que os mesmos sofrem durante os processos culinários e outros de preparação para o consumo. A técnica dietética tem como objetivo buscar um melhor aproveitamento nutricional dos alimentos por meio do conhecimento dos ingredientes e suas possibilidades de uso, bem como do estudo de diferentes técnicas culinárias $^{23}$. Portanto, a interação entre o planejamento da dieta (a prescrição dietética) e a refeição oferecida (a execução da prescrição) é uma atividade que está inserida no cotidiano da prática profissional dos nutricionistas ${ }^{24}$, fazendo parte de seu núcleo específico de competência.

Outro sentido apontado em algumas entrevistas foi a dificuldade em conseguir adesão às orientações, conforme o relato a seguir:

... eu acho que a maior dificuldade é você colocar, conseguir fazer com que o paciente coloque em prática o que você orienta, em relação a mudanças de há- 
bitos, inclusão de atividade física, diminuição do consumo de gorduras, sal, açúcares. Você vê que ele tem conhecimento, do que ele tá trazendo, do que é errado, mas é difícil por na prática! (Residente-16).

Relatos de literatura corroboram essas representações ao indicarem que a adesão dos pacientes a mudanças no estilo de vida, visando à prevenção e ao tratamento de doenças, como a adesão a uma dieta com restrições alimentares, é difícil de ser conseguida e, em geral, é baixa ${ }^{25}$.

Para Boog ${ }^{12}$, o despreparo da maioria dos profissionais de saúde para lidar com as questões alimentares leva à adoção de orientações simplistas e pouco práticas, pois, na maioria das vezes, preconiza-se a exclusão de muitos alimentos, contribuindo para a não adesão. A autora ressalta a necessidade de domínio, por parte dos profissionais, de métodos adequados para abordar os problemas alimentares e orientar a mudança de hábitos. Contudo, os profissionais das unidades estudadas não demonstraram ter esse domínio, como pode ser percebido no trecho. "... e até assim, o método de como fazer, alcançar, solucionar o problema. Às vezes, a gente fica muito limitado, a gente fica na orientação, mas eu não sei outros métodos" (Enfermeiro-11).

Sendo assim, a falta de adesão pode ser principalmente um reflexo da abordagem inadequada que está sendo feita. No processo de adesão, mais do que simplesmente cumprir determinações do profissional de saúde, os pacientes devem ter autonomia e habilidade para aceitar ou não as recomendações, tornando-se participantes ativos do processo de cura ${ }^{26}$.

Nesse contexto, a educação nutricional, conforme será discutido a seguir, pode ser considerada um item primordial no sentido de preparar o indivíduo para lidar com suas novas necessidades, garantindo sua participação efetiva no processo de prevenção da doença e de suas complicações. O trecho a seguir ilustra claramente o exposto:
Aí você vê várias diferenças em abordagem que explicam porque que não conseguiu nada. Então, entrega de papelzinho pronto, sem explicação, sem uma... Porque, às vezes, no serviço público, você precisa de algumas ferramentas, mas como usar, né? E vem disso também (Residente-17).

\section{Educação nutricional}

Os resultados evidenciaram a falta de clareza, por parte dos profissionais, quanto ao conceito de educação nutricional, sendo que a maioria dos profissionais de nível médio sequer conhecia o termo.

A despeito de concepções mais atuais ${ }^{10,27,28}$, a educação nutricional ainda apareceu fortemente representada, neste estudo, como uma estratégia para ensinar as pessoas a se alimentarem corretamente, como se pode perceber a seguir.

... eu entendo assim, é tá dando a orientação em como tá se alimentando, porque a gente tem o hábito de estar se alimentando super mal. Eu sou assim. Às vezes, tem uma dieta de um médico, o médico fala que tem que seguir, você acaba não seguindo. Então, o nutricionista vai te ajudar em como você tá vendo isso e fazer, assim, com que você segue aquilo lá, o que é a parte nutricional do paciente ou de qualquer pessoa que queira ter esse acompanhamento (ACS-6).

A educação nutricional também foi relacionada com a promoção da saúde e a prevenção de doenças.

... eu acho que educação nutricional também extrapola essa questão científica, bioquímica, extrapola pra questão da promoção e... promoção da saúde e prevenção de doenças. Que as comunidades percebam a nutrição de outra forma, que não a que foi conduzida, né? Porque nosso padrão nutricional mudou bastan- 
te. A humanidade mudou e a gente tem que mudar às vezes. A gente mudou pro pior, não? (risos) (Dentista-12).

Essa representação está de acordo com Santos $^{29}$, que enfatiza a importância da educação nutricional na promoção das práticas alimentares saudáveis, apontada como importante estratégia para enfrentar os novos desafios no campo da saúde, alimentação e nutrição. Boog ${ }^{12}$ também ressalta o papel da educação nutricional na promoção de hábitos alimentares saudáveis desde a infância.

Os resultados revelaram uma concepção de educação nutricional prescritiva, mostrando que os profissionais de saúde seguem o modelo de educação tradicional, que pretende mudar comportamentos individuais utilizando estratégias educativas verticais, com transmissão de conhecimentos de forma unilateral, ou seja, uma "educação bancária", na qual o educador é o detentor do saber, e o educando deve aprender passivamente os conceitos ensinados ${ }^{30}$.

... você saber, assim, o que você pode, o que você não pode. De que maneira você pode ... Pra mim, educação é isso (ACS-20).

No entanto, no presente trabalho, as representações obtidas acerca da educação nutricional distanciaram-se consideravelmente das proposições teóricas, evidenciando práticas verticais e prescritivas, baseadas essencialmente na transmissão de conhecimentos técnicos, revelando que a área carece de maior capacitação e discussão por parte dos profissionais das equipes de saúde da família do município estudado.

Conforme exemplificado a seguir, foi possível perceber que os profissionais das unidades pesquisadas desconhecem - ou simplesmente não utilizam - metodologia específica para as ações de educação nutricional, revelando uma representação de que, para a sua prática, não é necessário planejamento nem tampouco capacitação na área.

Então, essa questão de educação nutricional, eu acho que a gente faz indivi- dualmente um tanto, da maneira como cada um entende, né? (Dentista-12).

Essa concepção está de acordo com o pressuposto de Santos ${ }^{29}$, para quem o campo da educação nutricional ainda demanda maiores discussões sobre metodologias de ensino-aprendizagem adequadas para sua prática, a fim de que a temática seja inserida no âmbito da atenção básica, mais especificamente na ESF.

Vale lembrar que, para a promoção da alimentação saudável, as propostas educativas não devem estar focadas somente na disseminação de informações, ou seja, na oferta de informações e conteúdos técnicos de alimentação e nutrição, em detrimento da capacitação em abordagens educativas apropriadas. O conhecimento técnico não pode substituir a educação, que tem no diálogo um de seus elementos centrais. Esse diálogo é que oferece sentido para as ações educativas e para o processo de mudança das práticas alimentares dos indivíduos ${ }^{29}$.

\section{Problematizando a ausência do nutricionista na equipe de saúde da família}

Considerando que as ações de alimentação e nutrição devem estar contempladas em qualquer ação de saúde, relacionadas tanto à promoção quanto ao cuidado, em todos os níveis de atenção e em todas as etapas da vida ${ }^{4,19}$, a presente seção trata da concepção dos profissionais quanto à ausência do nutricionista nas equipes de saúde da família.

Os depoimentos obtidos revelaram opiniões divergentes quanto à inclusão do nutricionista nas equipes de saúde da família. Por um lado, alguns profissionais relataram ser importante e necessária a inclusão do profissional na equipe mínima, no sentido do fortalecimento das potencialidades do conhecimento da nutrição e das intervenções nesse campo. Essa representação está de acordo com o Conselho Federal de Nutricionistas, que estabelece que algumas ações, 
como a assistência nutricional especializada e a educação nutricional, são de competência do nutricionista, pois dizem respeito a seu conhecimento técnico específico e, portanto, a rede de serviços públicos de saúde não pode prescindir desse profissional4.

Por outro lado, alguns profissionais manifestaram que, quando há outro profissional para o qual possam encaminhar, mesmo que este não seja exclusivo e nem mesmo integrante formal da equipe de saúde da família, como o residente, isso é o suficiente para suprir a necessidade de atendimento à população. Assim, de acordo com essa concepção, o nutricionista não seria necessário em período integral na unidade, pois poderia capacitar os profissionais da equipe a lidarem com seus pacientes de maneira mais ampla, com os conhecimentos específicos dessa área, conforme exemplificado nas falas desses entrevistados.

Tudo bem, a gente até entende que ele não venha todos os dias, que ele não esteja aqui para atender consulta, mas pra orientar mais, pra gente ter mais espaço de capacitação, um suporte pra gente poder dar a orientação até aonde a gente pode ir, quando a gente percebe que existe uma resistência muito grande, aquela dificuldade, 'olha, tem que ser você mesmo, você é que tem o jeito pra isso' (ACS-26).

Idealmente até poderia pensar, mas... eu penso que se não for possível integrar, cada equipe ter o seu, a ideia do matriciamento que a gente vem trabalhando e tentando implantar, ela é o ideal, porque você teria o profissional de referência pra duas ou três equipes, que fosse, e, através do matriciamento, isso se daria fortalecendo a equipe, empoderando a equipe nisso, porque se você pensar numa equipe que atende aí 3 mil pessoas, através do matriciamento, você teria 3 equipes conversando com 1 nutricionista, que conseguiria dar conta aí de 9 mil pessoas, né? Então, eu acho que idealmente até seria interessante tê-lo, mas através do matriciamento, isso acho que já é o suficiente pra gente melhorar ... (Diretor-25).

Tais relatos apontaram para uma organização da atenção nutricional, na rede básica de saúde do município de São Carlos (SP), no formato de apoio matricial, no qual o nutricionista não é visto como alguém que deve atender diretamente aos usuários, mas apenas "como o detentor de um conhecimento técnico, muito específico, que deve ser repassado a outros profissionais que farão o atendimento"12 (p.144).

Os entrevistados referiram-se à falta de vontade política dos gestores de saúde em relação à abertura de campo de trabalho para o nutricionista, mostrando que eles ainda não se sensibilizaram a respeito da importância da atuação desse profissional.

Aliada à questão política, também se atribuiu a ausência do nutricionista na ESF a fatores como falta de verba para sua contratação, baixo reconhecimento social e desvalorização profissional.

Na perspectiva de $\mathrm{Boog}^{31}$, a inclusão do nutricionista nas equipes de saúde da família também depende das representações que os gestores constroem a respeito da sua atuação, o que vai determinar a maior ou menor importância dada a esse profissional.

É importante considerar que fatores de natureza subjetiva como a opinião dos gestores acerca do valor da intervenção, do potencial de resolutividade dela a curto, médio e longo prazos e a representação que eles têm sobre o papel que o nutricionista pode ou deve desempenhar são tão ou mais significativos na tomada de decisão sobre a incorporação do profissional na equipe, do que a necessidade e disponibilidade de profissionais na região, e a avaliação dessa necessidade dificilmente será realizada sem sofrer a influência dos centros de interesse e de poder $^{31}$ (p.34). 
Nesse sentido, cabe destacar trechos importantes da entrevista do responsável pela gestão da atenção básica no município estudado.

Eu acho que ... quantos anos tem a profissão de nutricionista? Ela já nasce numa concepção de ... lembra que eu falei no começo que é a coisa da elitização? Então, e da nutricionista, é um profissional de elite. Porque as políticas públicas nunca trouxeram muito isso. E talvez por... . Qual é a proposta de saúde que se tem? Quando a gente faz uma atenção à saúde médico-centrada, não vai sobrar espaço para mais ninguém, entendeu? Só o enfermeiro como auxiliar do médico ... . Nós vínhamos sempre dessa proposta: atenção médico-centrada. Se é médico-centrada vai ser queixa-conduta, e aí sim a equipe de enfermagem vai sempre ser valorizada por quê? Porque tem que fazer aquilo que o médico determinou, operacional. É assim, sempre foi. A saúde, a atenção à saúde, esse é o nosso, a quebra desse paradigma ... atenção à saúde não se faz com um único profissional que é o médico... . Se eu tenho uma atenção médico-centrada, eu não preciso dos demais, e eu não vou fortalecer isso. Então, as políticas hoje, a estratégia de saúde da família vem nessa direção, ela vai ter que desconstruir esse conceito de atenção à saúde médico-centrada, e passar pra questão da multidisciplinaridade, multiprofissionalismo, etc., cada um dando a sua contribuição. É isso que a gente acredita. E aí sim, nessas novas políticas, eu acho que a inserção do fono, do fisio, do T.O., do nutricionista, ele vai se dar. Essa é a construção, eu acho que na cabeça dos profissionais primeiro, que muitas vezes a gente age dessa maneira, fortalecendo ou jogando no colo do outro porque é muito mais fácil, se eu jogo no colo do outro, a responsabilidade é do médico e ponto, a responsabilidade fica dele e eu me livrei, eu não vou ter que me envolver. Então isso é uma construção, essa é uma mudança também de trabalhar da equipe. Então, eu acho que é essa coisa do respeito profissional que a gente ainda tem que aprender. Difícil, né? Bem difícil. Mas essa é a nossa meta. Senão, se a gente desistir, não vale a pena estar aqui [...] é ter respeito entre os profissionais, cada um respeitar o domínio profissional do outro (Diretor-25).

O discurso ressalta fatores importantes a serem considerados na construção da representação do fazer teórico-prático do nutricionista pelos demais profissionais, como o tempo de existência da profissão de nutricionista, o modelo médico-hegemônico e o processo de construção de uma nova proposta de atenção à saúde.

Nesse sentido, os sujeitos entenderam que a incorporação efetiva do profissional nutricionista, assim como de outros profissionais não contemplados na equipe mínima da ESF, parece ser uma "questão de tempo", visto que os próprios gestores vêm propondo diferentes arranjos para incluir esses profissionais nas equipes, como por exemplo, no formato de equipes matriciais e nos NASF. Dessa forma, estar-se-ia vivenciando um processo de "amadurecimento do SUS", ou seja, um processo de construção de uma nova proposta de atenção à saúde, baseada na integralidade, no trabalho em equipe multiprofissional e na interdisciplinaridade.

Eu acho que isso é uma coisa que vai pelo tempo, sabe? Porque, como você falou, até então não tinha e agora tem, e acho que isso tende a crescer, porque cada dia mais a gente vê a necessidade de outros profissionais, descentralizando do médico, que, até então, era tudo centralizado no médico. Eu acho que isso é uma coisa que vai crescer ainda (ACS-7).

Olha... no caso desse profissional especificamente... eu poderia dizer até de vários profissionais, eu acho que é uma própria questão de amadurecimento do SUS. Eu 
acho que o SUS, através dos seus gestores, tem visto a necessidade de uma melhor formação desses profissionais pra tá trabalhando em equipe (Médico-10).

Vários profissionais entrevistados atribuíram a ausência do nutricionista na ESF a uma "banalização da profissão", ou seja, à representação de que, culturalmente, a nutrição seria uma profissão menos técnica e menos especializada que as demais da área da saúde, por envolver uma atividade ligada à cotidianidade e ao senso comum - a alimentação. Tais relatos confirmaram os resultados de Boog ${ }^{8}$, que discutiu a ausência do profissional nutricionista nos serviços públicos de saúde, questionando se ela seria devida à dificuldade inerente à própria atividade que, por estar tão estreitamente ligada à esfera do cotidiano, seria tida como "não técnica" ou "pouco científica".

Contudo, os resultados do presente estudo revelaram alguns questionamentos quanto à concepção da Nutrição como profissão pouco técnica, apontando para um movimento de mudança nessas representações. Dessa forma, a ideia de que "qualquer médico sabe orientar dieta" parece perder a força e começa a ser entendida como uma das possíveis causas da falta de adesão às orientações nutricionais.

... qualquer médico sabe orientar uma alimentação perfeita. Mentira, porque cada vez mais eu tenho consciência de que não é nada disso, se perdem muitas coisas muito importantes. Não só na orientação, como no jeito que você desenvolve, que o paciente adere, que normalmente é mais vertical, sem fundamento. Então, eu posso fazer 200 mil orientações e o cara vai embora e vai comer uma costela na hora do almoço, entendeu? Eu acho que falta esse incentivo sim, aqui a gente só tem um nutricionista na rede (Residente-1).

Ficou claro, em várias entrevistas, que os profissionais da equipe resolvem, mesmo que inadequadamente, o problema da falta de outras categorias profissionais, evitando assim que a demanda apareça. Dessa forma, a não inserção do nutricionista nas equipes de saúde da família abre espaço para que outros profissionais se apropriem de forma inadequada ou superficial do conhecimento sobre nutrição, tentando suprir essa falta, mesmo que conscientes de que não possuem formação adequada na área.

A não incorporação de outras categorias profissionais nas equipes de saúde da família faz com que se perpetue o modelo médico-hegemônico, onde a atenção é centralizada nos procedimentos e na figura do médico, como exemplifica o próximo depoimento.

Olha, eu acho assim, a área de saúde, ela ainda tá no modelo antigo, onde o importante é o médico, tá certo? É o médico, e depois o enfermeiro. Essas são as duas figuras do modelo de saúde, e, por mais que a gente tente mudar isso, eu acho que politicamente, eles acabam reforçando o modelo antigo, certo? Então, tanto a gestão local como o governo mesmo, em todos os níveis, eu acho que eles têm o discurso de fazer uma equipe multiprofissional, co-gestão, mudar o modelo, fazer vínculo, mas no final das contas, se reforça a questão do médico e do enfermeiro dentro da unidade. Se reforça o quê? O médico como assistencialista que vai ficar lá e vai atender todo mundo e o enfermeiro como quem comanda a unidade (Enfermeiro-5).

Assim, a fala a seguir revelou um grande paradoxo: por um lado, o discurso oficial propõe o trabalho em equipe multiprofissional e interdisciplinar, buscando uma atenção integral, e, por outro lado, reforça-se o antigo modelo do médico centrado, pois não se investe na contratação de outros profissionais além do médico e do enfermeiro.

Porque o discurso é um, na prática é outro. O discurso é: nós vamos valorizar equipe, não mais médico centrado, mas, na prática, o quê que se valoriza? O trabalho do médico. O curativo (Residente-19). 
104 ACA CAMOSSA et al.

\section{O N CLUSÃ O}

Tendo em vista o objetivo inicial de conhecer as representações sociais dos profissionais de equipes de saúde da família sobre o fazer teórico-prático do nutricionista, pode-se considerar que tais representações concebem o nutricionista como um profissional de saúde importante e necessário nas USF.

O estudo apontou que os sujeitos pesquisados atribuíram ao profissional nutricionista a função primordial de realizar atendimentos individuais nos vários ciclos de vida, elaborando e orientando dietas para patologias específicas, especialmente para doenças crônicas, como diabetes Mellitus e hipertensão arterial. Essa situação tem contribuído para consolidar o papel do nutricionista como prescritor de dietas, dificultando que se construa a visão de que ele pode contribuir mais amplamente para a promoção da saúde.

Os resultados também revelaram que a maioria dos profissionais de saúde sente-se despreparada para lidar com as questões alimentares. Dessa forma, quando é demandada, a orientação nutricional é realizada de uma forma rápida, simplificada e pouco prática, frequentemente preconizando-se a exclusão de muitos alimentos por meio de "listas de alimentos proibidos", o que pode levar à não adesão dos pacientes.

Não parece haver dúvidas sobre a importância da educação nutricional na promoção de práticas alimentares saudáveis, na prevenção de doenças e na recuperação da saúde. No entanto, o estudo mostrou uma visão muito superficial e pouco abalizada teoricamente sobre a educação nutricional, e raras foram as ações realizadas sistemática e continuamente nas USF estudadas. As poucas iniciativas encontradas foram desenvolvidas por médicos, enfermeiros e residentes, e ficou evidente que o enfoque das ações estava prioritariamente na transmissão de informações sobre aspectos biológicos da alimentação. Dessa forma, foi possível perceber uma grande lacuna entre a teoria e a prática da educação nutricional nas USF pesquisadas.

Deve-se considerar, também, que os resultados sugeriram uma concepção do fazer teórico-prático do nutricionista embasada em um maior conhecimento sobre suas funções e atribuições, demonstrando um possível movimento de mudança nas representações sociais construídas pelos profissionais da ESF. A inserção da categoria no programa de residência multiprofissional muito provavelmente contribuiu para uma maior aproximação da equipe com os profissionais de nutrição. Também foi possível inferir que experiências como as residências multiprofissionais são positivas, no sentido de proporcionar mudanças no comportamento dos profissionais da equipe mínima em relação às questões e condutas referentes à nutrição dos indivíduos e famílias atendidos pelo programa.

A ausência do nutricionista na equipe de saúde da família foi atribuída a fatores como falta de reconhecimento governamental, falta de recursos financeiros, baixo reconhecimento social, desvalorização profissional, pouco tempo de existência da profissão, desconhecimento do núcleo de competência do nutricionista e manutenção do modelo médico-hegemônico.

Avaliou-se como adequada aos propósitos da pesquisa a metodologia escolhida. As entrevistas constituíram-se em oportunidades para os profissionais pensarem sobre a atuação do nutricionista na ESF, suscitando possíveis questionamentos a esse respeito. Nesse sentido, a experiência de terem sido sujeitos do presente trabalho pode tê-los levado a refletir mais sobre o fazer teórico-prático do nutricionista e, consequentemente, a respeitar mais esse profissional como integrante de equipes interdisciplinares de saúde na atenção básica.

Seria conveniente o desenvolvimento de novas pesquisas, seja problematizando a ausência de nutricionista nas equipes de saúde, especialmente na ESF, seja relatando as experiências desses profissionais nas equipes onde eles já foram inseridos de forma efetiva. 


\section{COLABORADORES}

ACA CAMOSSA trabalhou na concepção teórica e execução da pesquisa, análise e interpretação dos dados, elaboração, redação e formatação final do artigo. R TELAROLLI JR participou como orientador da pesquisa. MLT MACHADO participou como coorientadora da pesquisa e revisora da versão final do artigo.

\section{REFERÊ N CIAS}

1. Conselho Federal de Nutricionistas. Inserção profissional dos nutricionistas no Brasil. Brasília: CFN; 2006 [acesso 2006 dez 5]. Disponível em: <http:// www.cfn.org.br/pesquisa.pdf>.

2. Pádua JG, Boog MCF. Avaliação da inserção do nutricionista na Rede Básica de Saúde dos municípios da Região Metropolitana de Campinas. Rev Nutr. 2006; 19(4):413-24. doi: 10.1590/\$1415-527 32006000400001.

3. Bosi MLM. Profissionalização e conhecimento: a nutrição em questão. São Paulo: Hucitec; 1996.

4. Assis AMO, Santos SMC, Freitas MCS, Santos JM, Silva MCM. O Programa Saúde da Família: contribuições para uma reflexão sobre a inserção do nutricionista na equipe multidisciplinar. Rev Nutr. 2002; 15(3):255-66. doi: 10.1590/S1415-5273200 2000300001.

5. Brasil. Ministério da Saúde. Avaliação da implantação do programa de saúde da família: relatório preliminar. Brasília: MS; 1999.

6. Conselho Federal de Nutricionistas. O papel do nutricionista na atenção primária à saúde. Brasília: CFN; 2008 [acesso 2009 maio 3]. Disponível em: $<$ http://www.cfn.org.br>.

7. Brasil. Ministério da Saúde. Secretaria de Atenção à Saúde. Documento-base de subsídio do Seminário Estadual de Alimentação e Nutrição no SUS. Brasília: MS; 2010 [acesso 2010 mar 4]. Disponível em: <http://nutricao.saude.gov.br/documentos/ documentobase_semi_estadual.pdf $>$.

8. Boog MCF. Educação nutricional em serviços públicos de saúde: busca de espaço para ação efetiva [tese]. São Paulo: Universidade de São Paulo; 1996.

9. Monteiro CA, Mondini L, Souza ALM, Popkin BM. Da desnutrição para a obesidade: a transição nutricional no Brasil. In: Monteiro CA, organizador. Velhos e novos males da saúde no Brasil: a evolução do país e de suas doenças. São Paulo: Hucitec; 2000. p.247-55.

10. Boog MCF. Contribuições da educação nutricional à construção da segurança alimentar. Saúde Rev. 2004; 6(13):17-23.
11. Brasil. Ministério da Saúde. Secretaria de Atenção à Saúde. Política nacional de alimentação e nutrição. $2^{a}$ ed. Brasília: MS; 2003.

12. Boog MCF. Dificuldades encontradas por médicos e enfermeiros na abordagem de problemas alimentares. Rev Nutr. 1999; 12(3):261-72. doi: 10.1590/ S1415-52731999000300006.

13. Minayo MCS. O desafio do conhecimento: pesquisa qualitativa em saúde. $10^{a}$ ed. São Paulo: Hucitec; 2007.

14. Moscovici S. A representação social da psicanálise. Rio de Janeiro: Zahar Editores; 1978.

15. Guareschi P, Jovchelovitch S, organizadores. Textos em representações sociais. $8^{a}$ ed. Petrópolis: Vozes; 2003.

16. Cabecinhas R. Representações sociais, relações intergrupais e cognição social. Paidéia. 2004; 14(28): 125-37.

17. Machado MLT. História da saúde em São Carlos. São Paulo: Imprensa Oficial do Estado de São Paulo; 2007. Coleção Nossa História.

18. Archanjo LR, Brito KFW. Nutrição: gênero e profissão. RUBS [Internet]. 2005 [acesso 2010 jan 30], 1(4):44-50. Disponível em: <http://rubs.up.edu.br>.

19. Brasil. Ministério da Saúde. Secretaria de Atenção à Saúde. Matriz de ações de alimentação e nutrição na atenção básica de saúde. Brasília: MS; 2009.

20. Saar SRC, Trevizan MA. Papéis profissionais de uma equipe de saúde: visão de seus integrantes. Rev Latino-Am Enfermagem [Internet]. 2007 [acesso 2010 jan 30]; 15(1):106-12. Disponível em: <www. eerp.usp.br/rlae>.

21. Diez-Garcia RW. A Antropologia aplicada às diferentes áreas da nutrição. In: Canesqui AM, DiezGarcia RW, organizadores. Antropologia e nutrição: um diálogo possível. Rio de Janeiro: Fiocruz; 2005. p.275-86.

22. Castro IRR, Souza TSN, Maldonado LA, Caniné ES, Rotenberg S, Gugelmin AA. A culinária na promoção da alimentação saudável: delineamento e experimentação de método educativo dirigido a adolescentes e a profissionais das redes de saúde e de educação. Rev Nutr. 2007; 20(6):571-88. doi: 10.1590/S1415-52732007000600001.

23. Ornellas LH. Técnica dietética: seleção e preparo de alimentos. $8^{a}$ ed. São Paulo: Atheneu; 2006.

24. Sousa AA, Proença RPC. Tecnologias de gestão dos cuidados nutricionais: recomendações para qualificação do atendimento nas unidades de alimentação e nutrição hospitalares. Rev Nutr. 2004; 17(4):425-36. doi: 10.1590/\$1415-52732004000 400003. 
25. Assis MAA, Nahas MV. Aspectos motivacionais em programas de mudança de comportamento alimentar. Rev Nutr. 1999; 12(1):33-41. doi: 10.1590/ S1415-52731999000100003.

26. Pontieri FM, Bachion MM. Crenças de pacientes diabéticos acerca da terapia nutricional e sua influência na adesão ao tratamento. Ciênc Saúde Colet. 2010; 15(1):151-60. doi: 10.1590/S1413-812 32010000100021.

27. Ferreira VA, Magalhães R. Nutrição e promoção da saúde: perspectivas atuais. Cad Saúde Pública. 2007; 23(7):1674-81. doi: 10.1590/S0102-311X2 007000700019 .

28. Lima KA. Análise do processo de construção do conhecimento dietoterápico de pacientes diabéticos atendidos no programa saúde da família do município de Araras-SP [dissertação]. Araraquara: Universidade Estadual Paulista; 2004.

29. Santos LAS. Educação alimentar e nutricional no contexto da promoção de práticas alimentares saudáveis. Rev Nutr. 2005; 18(5):681-92. doi: 10.15 90/S1415-52732005000500011.

30. Freire P. Pedagogia da autonomia: saberes necessários à prática educativa. 30ª ed. São Paulo: Paz e Terra; 2004.

31. Boog MCF. Atuação do nutricionista em saúde pública na promoção da alimentação saudável. Rev Ciênc Saúde. 2008; 1(1):33-42.

Recebido em: 2/9/2010

Versão final reapresentada em: 3/5/2011

Aprovado em: 26/9/2011 